\title{
Investigating the Application of a Hybrid Space Discretisation for Urban Scale Evacuation Simulation
}

\begin{abstract}
The devastating effects of wildfires cannot be overlooked; these include massive resettlement of people, destruction of property and loss of lives. The considerable distances over which wild fires spread and the rates at which these fires can spread is a major concern as this places considerable challenges on the evacuation mechanisms that need to be put in place. It is therefore crucial for personnel, involved in evacuation planning, to obtain reliable estimates of evacuation times faster than real time, to assist their decision making in response to actual unfolding of events. In this work, we present a hybrid approach, which we refer to as the Hybrid Spatial Discretisation (HSD) for large scale evacuation simulation. The HSD integrates the three spatial representation techniques typically used for representing space usage in evacuation models; namely Coarse regions, Fine nodes and Continuous regions. In this work, we describe the core models constituting the HSD coupled with the approaches used for representing the transition of agents across the different spatial types. Using a large scale case, we demonstrate how the HSD can be used to obtain higher resolution of results where it is most required while optimising the use of available computational resources for the overall simulation. The HSD is seen to provide improvements in run times of more than $40 \%$ when compared to modelling the whole area using just the Fine node method.
\end{abstract}

Keywords: city evacuation, hybrid evacuation model, hybrid spatial discretisation, urban scale egress simulation

\section{Introduction}

Past incidents demonstrate that large wild fires can have very disastrous consequences including considerable loss and damage of property, resettlement of communities, injuries and in unfortunate cases fatalities. Examples of wild fire disasters include: Australia bush fire (year 2009, 180 fatalities) [1], Greece forest fire (year 2007, 65 fatalities) [1], USA Angora incident (2007, 245 homes destroyed) [2], USA Grass Valley and Slide fires (2007, 2180 homes destroyed) [2], Indonesia forest fire (year 1997, 240 fatalities) [1], Fort Mc Murray wildfire (year 2016, more than 2400 structures destroyed) [3]. Given the scale of the incidents and the large population sizes involved, the evacuation management problem can be very challenging. Moreover, the rates at which fires spread imply that evacuations need to take place very rapidly 
and efficiently [2]. Therefore, it is crucial for personnel, involved in evacuation planning, to obtain reliable estimates of times required to clear affected areas.

In large urban areas simply announcing an evacuation is often a difficult decision which officials have to make; as announcing evacuations too early and then later finding out that the danger has been averted may lead to unnecessary economic implications and inconveniences to the evacuees. Whereas, announcing evacuations too late may expose evacuees to potential life threatening situations. In such circumstances, officials can use evacuation time estimates to better plan evacuation announcements [4][5]. This is where the use of evacuation simulation tools becomes essential.

Computational evacuation tools present significant benefits as they can be used to harness both quantitative and qualitative information which include evacuation time estimates, space usage by evacuees, detection of hazardous situations and identification of alternate egress routes. As such, evacuation simulation tools can offer considerable assistance to a number of users including officials involved in the planning and design of emergency procedures, engineers and safety managers. However, evolving conditions as a result of the fires can deteriorate and decrease the capacity of certain evacuation routes. In such cases, relying on evacuation simulations that have been previously conducted might not be suffice as these may not be representative of the risks associated with the actual unfolding of events. Thus, it becomes more evident that evacuation simulation tools need to be capable of providing evacuation results faster than real time.

In all evacuation models, the space usage of the population needs to be modelled. These models typically use one of the three approaches for representing the space namely a coarse network of nodes, a fine network of nodes or continuous regions [6]. Models using a coarse spatial representation are referred to as macroscopic models that mainly represent the overall flow of evacuees without taking into consideration individual behaviours and movement. As such Coarse models have very fast execution times and can be scaled for large geometries. Fine node models allow the microscopic simulation of agent-based behaviours and movement but provide slower run times than Coarse models. Continuous models also allow microscopic simulations but at a higher resolution than Fine node models and therefore have the slowest execution times.

Scaling evacuation simulations for handling large enclosures with considerable population sizes presents considerable computational challenges. For example, previous studies have reported computational times of 56 hours for running large scale evacuation simulations [5]. Related work in the sphere of large scale evacuation modelling includes the use of the MATSim model for modelling large scale egress [7]. MATSim uses a combination of a graph model for agent route planning and a queue model for representing the movement is the agents as queues on links. Also, the movement of each individual agent can be controlled using a social forces model. The use of links reduces the numbers of paths which the agents can adopt and therefore the model can scale up to accommodate large geometries with large population sizes. 
In a study reported by Lindell, a large scale evacuation model (EMBLEM2) has been utilised to simulate the evacuation of people as a result of an impending hurricane [4]. The macroscopic representation of pedestrian movement and flow of vehicles used in this model accounts for its scalability for handling large scale evacuation. In another study, Lovreglio et al. have demonstrated the use of a multi-agent egress model (Pathfinder), using continuous space, for simulating the evacuation of a crowd as a result of toxic gas dispersion [8]. Moreover, a study conducted by Ronchi et al. demonstrated the application of the Pathfinder model for simulating the evacuation of up to 65000 agents in response to a bomb threat [9]. In the studies involving the continuous models, the run times of the simulations have not been mentioned. Given, the high fidelity of simulations run in continuous models, the run times can be assumed to be relatively high.

Our approach for handling large scale egress simulations differs by providing an integrated environment capable of representing the movement space at three resolutions namely coarse, fine node and continuous representation [10]. We refer to this approach as the Hybrid Spatial Discretisation (HSD). This approach allows the application of high resolution modelling to areas requiring high levels of quantitative and qualitative evacuation results, and low resolution modelling to areas in the far field. In this work, we demonstrate the application of the HSD to an urban scale geometry and demonstrate the benefits of the integrated model and the computational performance gains that can be harnessed.

\section{Related Work and Hybrid Spatial Discretisation}

Other developments in the field of evacuation modelling include the use of hybrid models which adopt a combination of different techniques to overcome limitations of a particular algorithm or method. An example of such a model is Evi [11], which is described as a hybrid model featuring characteristics of both macroscopic and microscopic modelling. This model incorporates both grid based techniques and social force models for representing agent movement in continuous space [11]. Another model using hybrid simulation techniques is described in Gloor et al. [12] which uses a combination of techniques namely potential field model and graph model for simulating pedestrian movement. This model uses the continuous space for representing the movement of agents.

Xiong et al. [13] presented a hybrid model comprising both of a macroscopic model for representing crowd movement patterns and a microscopic model for representing agent movement. The macroscopic model uses a speed-density relationship for selecting the crowd speed and the direction of the crowd is chosen based on the shortest paths. The information computed in the macroscopic model is then fed into the microscopic model, based on cellular automata, for simulating agent movement. Another study conducted by Xiong et al. [14] included a hybrid model in which they represented different segments of their geometry using either macroscopic or cellular automata. However, the hybrid model was demonstrated using only a simple corridor geometry in which two extremities of the corridor was modelled using cellular automata and the central part using macroscopic modelling. 
A study conducted by Tissera el al. [15] reported the development of hybrid model which uses a combination of an environmental sub-model to represent the propagation of smoke and fire and pedestrian model based on cellular automata for representing pedestrian movement. From the related work, it can be noted that the term 'hybrid' in relation to evacuation models has been used from different perspectives. In [11-13][15] the term hybrid has been used to describe the application of additional layers of functionality to the core model but the movement of the agents has been simulated using only one spatial type; whilst in [14], the term hybrid has been used to describe the combination of coarse regions and cellular automata to represent agent movement.

In our previous work [10], we demonstrated the application of a hybrid model, which we refer to as Hybrid Spatial Discretisation (HSD). The use of the term hybrid in relation to the HSD model differs from other studies in that it is capable of representing an additional level of resolution, i.e., HSD is capable of interfacing coarse regions, fine nodes and continuous regions as well. In contrast to the model presented in [14] which is applied to a simple corridor structure with only two configurations (Fine to Coarse and Coarse to Fine), the HSD can represent the interconnectivity between the three models is possible in all six possible configurations namely Fine to Coarse, Coarse to Fine, Fine to Continuous, Continuous to Fine, Coarse to Continuous and Continuous to Coarse. This multi-resolution approach has been demonstrated in a complex multiple compartment geometry [10]. In this work, an analysis of hybrid models was carried out. Table 1 shows the hybrid models investigated and some of their defining characteristics.

Table 1 Defining Characteristics of Hybrid models

\begin{tabular}{|c|c|c|}
\hline Model & Hybrid Feature & $\begin{array}{l}\text { Spatial representation } \\
\text { technique used }\end{array}$ \\
\hline $\mathrm{EVi}$ & $\begin{array}{l}\text { Combination of grid based and social } \\
\text { force models. }\end{array}$ & Continuous \\
\hline Gloor et al. & $\begin{array}{l}\text { Using potential field model and graph } \\
\text { model. }\end{array}$ & Continuous \\
\hline Xiong et al. & $\begin{array}{l}\text { Using a speed density relationship and } \\
\text { cellular automata movement model. }\end{array}$ & Fine \\
\hline $\begin{array}{l}\text { Xiong et al. } \\
\text { revised }\end{array}$ & $\begin{array}{l}\text { Using different segments of a geometry } \\
\text { using either Coarse or cellular automata } \\
\text { movement model. Demonstrated on } \\
\text { simple corridor with two types of } \\
\text { transitions. }\end{array}$ & Fine and Coarse \\
\hline Tissera et al & $\begin{array}{l}\text { Combination of environmental and } \\
\text { pedestrian sub models. }\end{array}$ & Fine \\
\hline HSD & $\begin{array}{l}\text { Using different segments of a geometry } \\
\text { using Coarse, cellular automata or } \\
\text { Continuous regions. Demonstrated on } \\
\text { complex multiple compartment building } \\
\text { with all six possible types of transitions. }\end{array}$ & Fine, Coarse, Continuous \\
\hline
\end{tabular}


The flexibility of the HSD model presents several benefits in terms of the size, performance and accuracy of egress problems that can be handled, as illustrated in Table 2:

Table 2 Proposed Application of HSD to different geometry scales

\begin{tabular}{|c|c|c|c|}
\hline $\begin{array}{l}\text { Scale of } \\
\text { Geometry }\end{array}$ & Configuration & $\begin{array}{l}\text { Discretisation } \\
\text { Strategy }\end{array}$ & $\begin{array}{l}\text { Rationale for spatial } \\
\text { representation used }\end{array}$ \\
\hline $\begin{array}{l}\text { Urban } \\
\text { environments }\end{array}$ & $\begin{array}{l}\text { Fine and } \\
\text { Coarse }\end{array}$ & $\begin{array}{l}\text { Coarse regions used to } \\
\text { map regions where } \\
\text { homogeneous crowd } \\
\text { movement and } \\
\text { behaviours are } \\
\text { expected. Fine nodes } \\
\text { used for regions where } \\
\text { heterogeneous } \\
\text { interactions are more } \\
\text { likely to occur. }\end{array}$ & $\begin{array}{l}\text { The use of coarse regions } \\
\text { for areas not central to the } \\
\text { analysis improves the } \\
\text { overall computational run } \\
\text { time while still being able } \\
\text { to higher resolution results } \\
\text { (due to the fine nodes) } \\
\text { where they are most } \\
\text { required. } \\
\text { Solving problems on such } \\
\text { a large scale would not be } \\
\text { feasible using only } \\
\text { continuous or fine nodes } \\
\text { due to the demanding } \\
\text { computational } \\
\text { requirements. } \\
\text { Using only Coarse regions } \\
\text { for problems of such sizes } \\
\text { would lead to reduced } \\
\text { fidelity of results. This is } \\
\text { because the Coarse model } \\
\text { is not able to capture } \\
\text { complex interactions at } \\
\text { junction/intersections or } \\
\text { areas of contraflows. It is } \\
\text { most appropriate in areas } \\
\text { where there are } \\
\text { homogeneous behaviours } \\
\text { for e.g. uni-directional } \\
\text { flows. }\end{array}$ \\
\hline $\begin{array}{l}\text { Large } \\
\text { Complex } \\
\text { Buildings }\end{array}$ & $\begin{array}{l}\text { Fine and } \\
\text { Continuous }\end{array}$ & $\begin{array}{l}\text { Pinch points, internal } \\
\text { and external exits } \\
\text { using Continuous and } \\
\text { remainder of geometry } \\
\text { using Fine. }\end{array}$ & $\begin{array}{l}\text { Provides higher resolution } \\
\text { of results (using the } \\
\text { Continuous) but without } \\
\text { large computational } \\
\text { overheads. }\end{array}$ \\
\hline
\end{tabular}




\begin{tabular}{|l|l|l|l|}
\hline & & & $\begin{array}{l}\bullet \\
\text { Improved accuracy when } \\
\text { compared to All-Fine } \\
\text { Higher computational } \\
\text { performance when } \\
\text { compared to All- } \\
\text { Continuous }\end{array}$ \\
\hline $\begin{array}{l}\text { Moderately } \\
\text { large problems } \\
\text { e.g. Large } \\
\begin{array}{l}\text { Transportation } \\
\text { Hub. }\end{array}\end{array}$ & $\begin{array}{l}\text { Fine, Coarse } \\
\text { and }\end{array}$ & $\begin{array}{l}\text { Pinch points, internal } \\
\text { and external exits } \\
\text { using Continuous. } \\
\text { Areas that are not } \\
\text { central to the analysis } \\
\text { using Coarse. } \\
\text { Remainder of } \\
\text { geometry using Fine. }\end{array}$ & $\begin{array}{l}\text { Provides higher resolution } \\
\text { of results (using the } \\
\text { Continuous) but without } \\
\text { large computational } \\
\text { overheads. }\end{array}$ \\
& & $\begin{array}{l}\text { Improved accuracy over an } \\
\text { All-Coarse } \\
\text { Higher computational } \\
\text { performance when } \\
\text { compared to All- } \\
\text { Continuous }\end{array}$ \\
\hline
\end{tabular}

\section{Hybrid Spatial Discretisation}

The HSD has been implemented in the buildingEXODUS evacuation model as it fulfilled several criteria; including ease of software integration and testing, by providing a modular platform capable of integrating new model functionalities. Moreover, the buildingEXODUS model has been validated in numerous studies [16-19] and it also provided a computational shell with an extensible Graphical User Interface (GUI). In this section, we present an overview of the core models employed in the HSD, which is as illustrated in Figure 1.

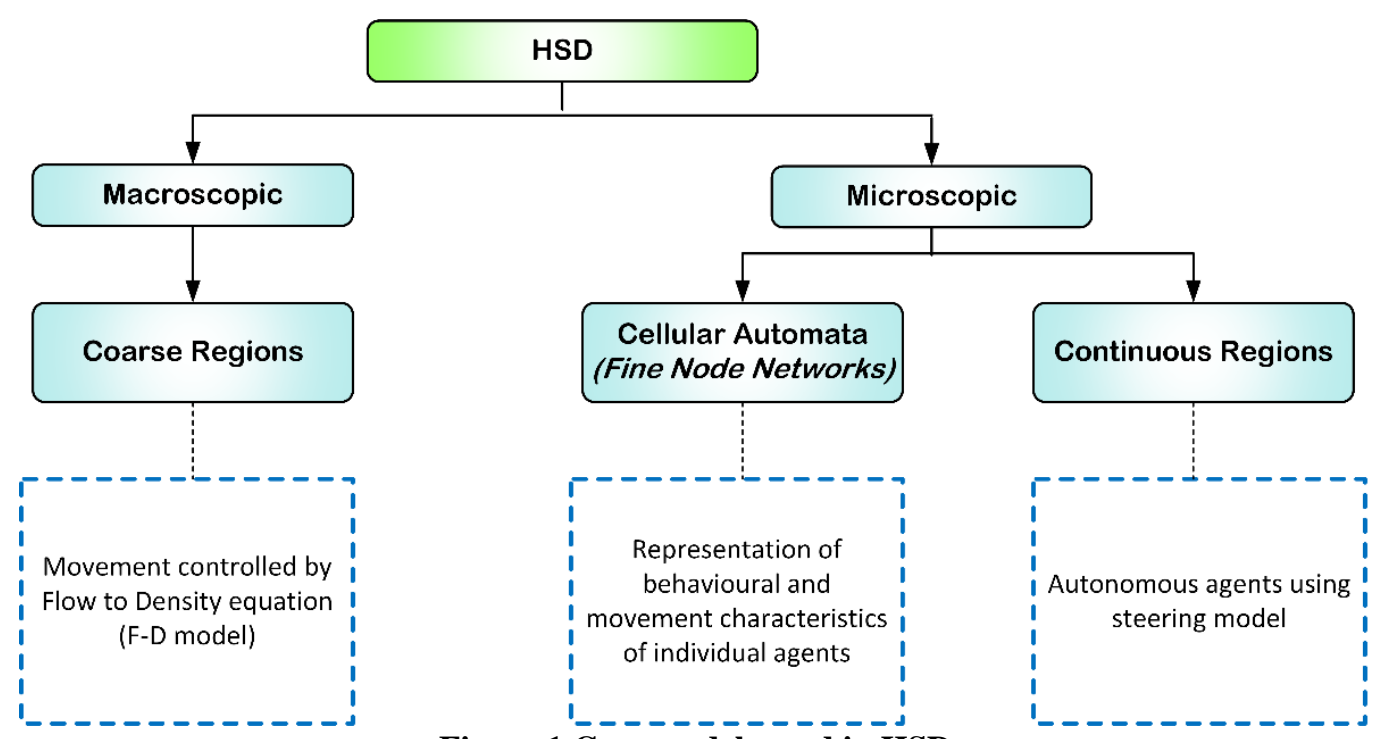

Figure 1 Core models used in HSD 


\subsection{Fine}

The Fine node model forms the core of the buildingEXODUS model which discretises the space into a two-dimensional grid of nodes interconnected by arcs. As such, the Fine model allows the representation of agents from an individual perspective. Agent movement is controlled using a potential map which generated in the pre-processing phase. During the map creation, potential values (representing the distance of the node from the nearest exit) are assigned to the nodes. The potential map for a multi-compartment building is shown in Figure $2[20]$.

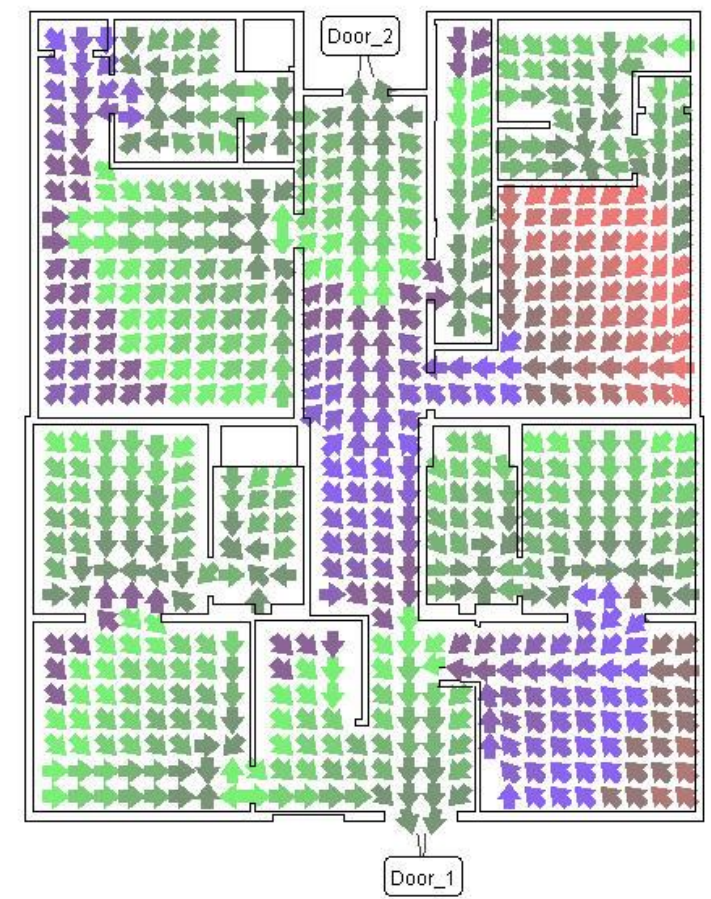

Figure 2 Potential map for a multiple compartment building

The discrete nature of this model allows fast computation of agent to agent and agent to structure interactions especially when these interactions are in the near field. Representing such interactions with elements that are further away increases the computational burden. Hence, the model utilises zones such as signage [21], compartment zones and escalator catchment areas for local behavioural routines. The Fine node model has been used to simulate external large crowd situations such as for the Beijing Olympics and more recently for the Hajj [22]. For example, running a simulation involving between 25,000 and 26,000 agents, with a geometry of $51,500 \mathrm{~m}^{2}$, required 1.5 hours of computation time to complete on a $3.6 \mathrm{GHz}$ processor with 8 GB of RAM [22].

The maximum densities that can be represented in the fine node model are limited due to the fixed dimensions of the arcs and nodes. Given the occupancy of one agent per node and the node spacing of $0.25 \mathrm{~m}^{2}$, the highest density that can be achieved is 4 persons $/ \mathrm{m}^{2}$. This level 
of density is considered acceptable for moving and normal static crowds. For example, Oberhagemann [23] found that even at a very slow walking pace, the maximum crowd density observed is 2.5 persons $/ \mathrm{m}^{2}$, and for static crowds, the Green Guide [24] recommends a maximum density of 1.5 persons $/ \mathrm{m}^{2}$ in areas that are used for viewing and circulation. Furthermore, several pieces of empirical work have been examined [25-27] that indicate that an individual's movement becomes constrained by the developing crowd at a population density of approximately 4.0 persons $/ \mathrm{m}^{2}$.

\subsection{Continuous}

The continuous model provides the highest resolution in HSD. Each pedestrian in the continuous model is represented as an autonomous agent that can perceive its environment and the obstacles within and other agents in its vicinity. All the information captured by agent perception system is fed into the behavioural engine which in turns triggers the movement mechanisms. The agent movement is based on a steering model [28].

As such, each agent has a property set as shown in Equation 1

$$
\begin{gathered}
S=\left\{x, y, v_{x}, v_{y}, h_{x}, h_{y}, a_{x}, a_{y}, \theta,\right. \text { body_width } \\
\text { perception, neighbours, obstacles, familiarity }\}
\end{gathered}
$$

Equation 1 Property Set of Continuous Agent

Where:

$\begin{array}{ll}x \text { and } y & : \text { Current agent position } \\ v_{x} \text { and } v_{y} & : \text { Velocity } \\ h_{x} \text { and } h_{y} & : \text { Heading } \\ a_{x} \text { and } a_{y} & : \text { Acceleration } \\ \theta & : \text { Angle of vision of agent } \\ \text { perception } & : \text { Distance perceived by agent } \\ \text { neighbours } & : \text { Neighbouring agents in perception } \\ \text { obstacles } & : \text { Wall boundaries and other obstacles } \\ \text { familiarity } & : \text { Agents can assign more priority to familiar exists. In absence of familiar } \\ & \text { exits, agents select the nearest ones by default }\end{array}$

The route choice of the agents is simulated using a Navigational Graph which is automatically generated in the pre-processing phase. A similar graph has been used in Gloor et al. [12]. Unlike the graph generation algorithm in Gloor et al., the one in HSD- Continuous does not generate redundant waypoints. The Navigational Graph for a complex multiple compartment building is shown in Figure 3. This graph simplifies the way-finding of the agents by providing waypoints to guide the agents towards their goal locations. The positioning of the waypoints also ensures that the agents maintain a separation from the walls. In addition, these waypoints 
help in reducing the number of computationally expensive wall detection checks that need to be performed by the agents.

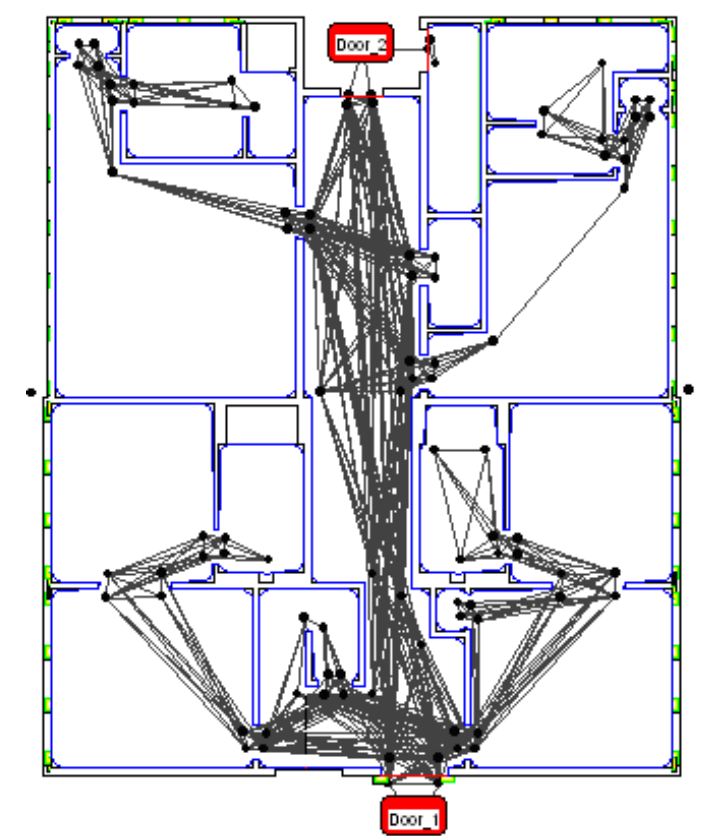

Figure 3 Navigational Graph in Continuous Model

Each agent uses its perception system to detect the presence of other neighbouring agents which can potentially influence its behaviour. In Figure 4, agent $\mathrm{P}$, scans the space ahead using a perception field whose length is proportional to its travel speed. This allows faster moving agents to respond quicker to neighbouring agents. The resulting steering vector $\mathrm{Vr}$ causes agent $\mathrm{P}$ to modify its path to avoid collision with the slower moving agent P1. The approach here also applies fast decay such that neighbouring agents that are further away have lesser influence on the path of $\mathrm{P}$.

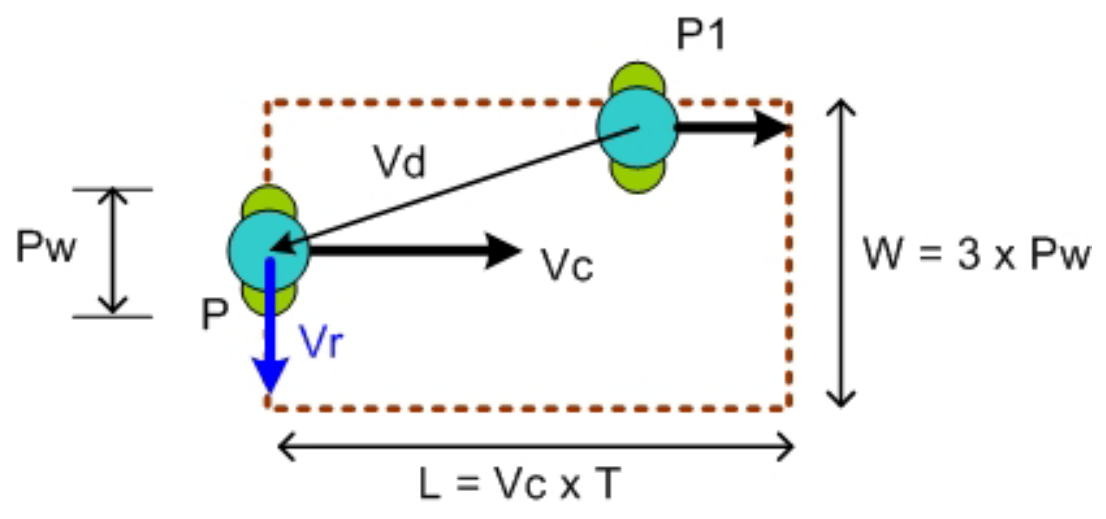

Figure 4 Perception of Agent in Continuous Model 
Where:

$\mathrm{Vc} \quad$ : Velocity vector of $\mathrm{P}$

Vd : Vector from P1 to P

$\mathrm{Vr} \quad$ : Resultant steering vector

Pw : Width of P

L $\quad$ : Length of Perception field

W : Width of Perception field

$\mathrm{T} \quad$ : Constant time for projecting the current velocity $\mathrm{Vc}$

The continuous model also uses an underlying spatial hashing technique, comprising of a grid, to optimise the search of agents in the continuous space. This grid is generated in the preprocessing phase and consists of cells, each capable of accommodating multiple agents (Figure 5). During runtime, the agents are allocated to the cells or de-allocated from them depending on their location. The use of the underlying grid causes a significant improvement in the performance by bringing down the computational complexity from $\mathrm{O}\left(N^{2}\right)$ to $\mathrm{O}(N M)$ [12] where $\mathrm{N}$ is the number of agents in the simulation and $\mathrm{M}$ is the total number of agents in current and neighbouring cells.

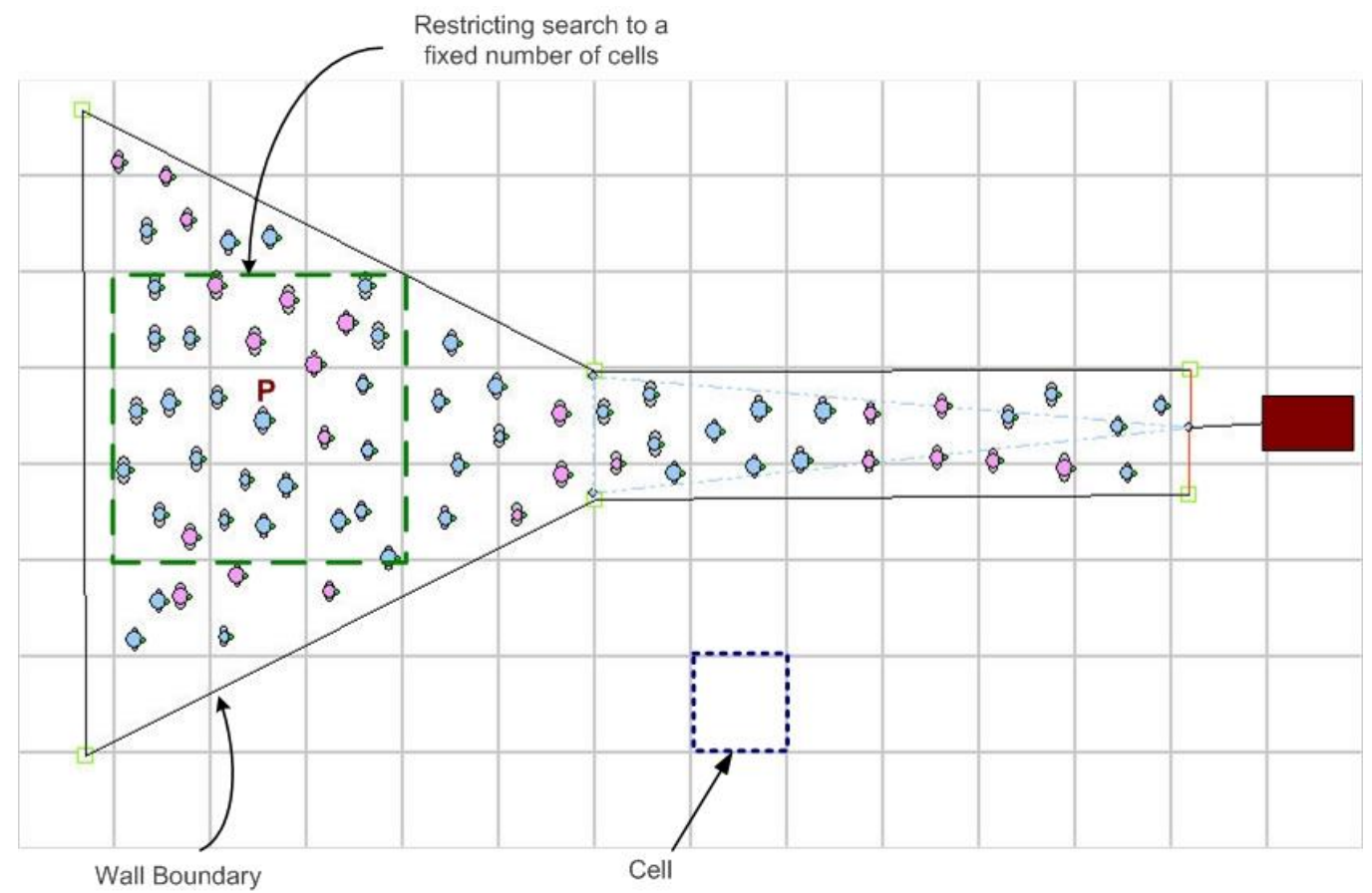

Figure 5 Optimising the searching of agents using underlying grid

\subsection{Coarse}

The Coarse model allows the available space to be segmented into regions to represent different sections of the geometry. Interconnectivity across the different regions are done using arcs 
which have a maximum flow capacity. In this model, the agents are represented as a homogenous ensemble which navigate across the arcs such that the individual movement and inter-agent interactions are not explicitly represented. The flow rate of the agents through a Coarse region varies according to parameters such as population density in region, travel speed and travel distance. The flow of agents is based on the F-D model [29] which is illustrated in Equation 2.

$$
t=t_{0}+A \cdot\left(\frac{V}{C}\right)^{n}
$$

Equation 2 F-D model used in Coarse model

Where:

t : Travel time (seconds) at flow level V

$\mathrm{t}_{0} \quad$ : Free-flow travel time (seconds)

V : Occupants demand (pass $/ \mathrm{m} / \mathrm{hr}$ ) or density (pass $/ \mathrm{m}^{2}$ )

C : Max Capacity (pass $/ \mathrm{m} / \mathrm{hr}$ or pass $/ \mathrm{m}^{2}$ )

A and $n \quad$ : Constants estimated in the model fitting process

The travel speed is then computed using the following equation:

$$
s=\frac{l}{t}
$$

Equation 3 Travel speed calculation in Coarse model

Where:

$s \quad:$ Estimated speed $(\mathrm{m} / \mathrm{s})$

$l \quad$ : Travel distance $(\mathrm{m})$

The parameters in Equation 2 can be adjusted to account for different types of Coarse regions such as Compartment, Gates, Interchange, Intersection, Stairs, Escalators and Travelators [20].

The core data structure used for agent movement in the Coarse model is based on a Navigational Graph, which is similar to the one used for the Continuous model. The arcs and waypoints generated in the graph guide the flow of agents towards target locations. The navigational graph is also generated for non-convex regions as shown in Figure 6. 


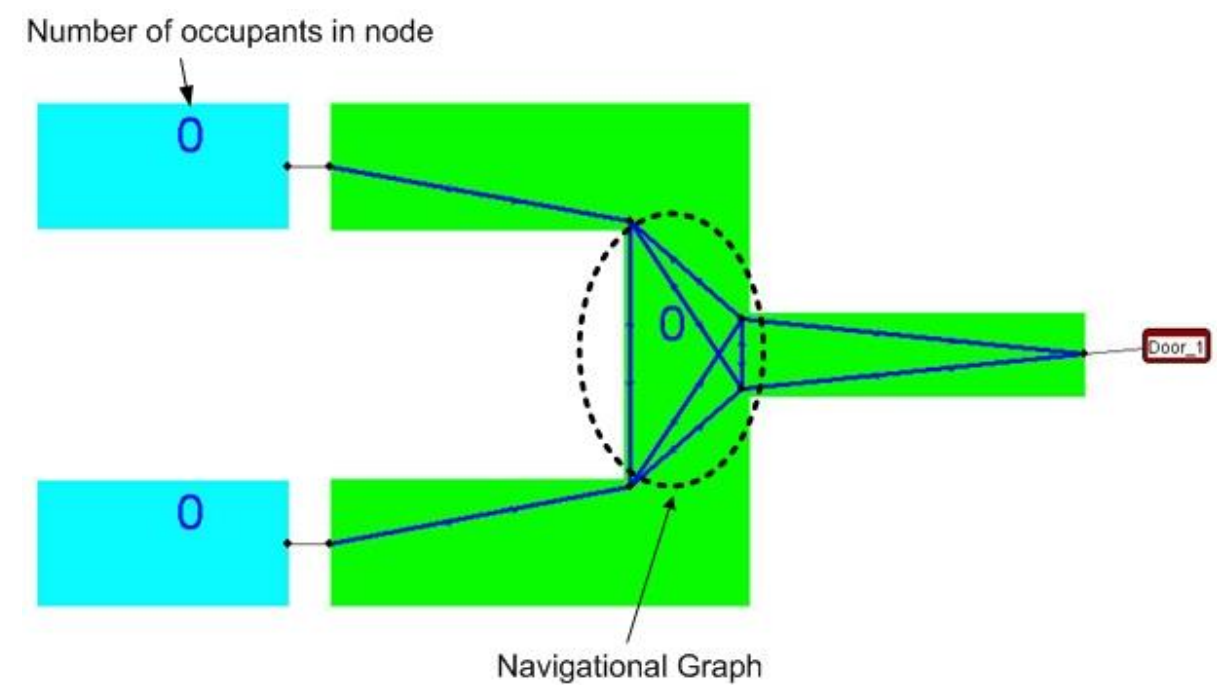

Figure 6 Navigational Graph in Coarse Regions

It is to be noted that although the graphical output of the Coarse regions only show the current capacities of the regions, the algorithmic procedures monitor the individual identities of the agents as well as their locations along the arcs. This enables the Coarse regions to be interfaced with other spatial representation types.

\subsection{Transition Regions}

When generating the population for a simulation, the agents can be positioned across the different sections of the geometry, which can be represented by the different spatial types. The simulation uses sequential calculation for executing the algorithmic routines for each agent. In order to integrate the macroscopic (Coarse regions) and microscopic (Fine node networks and Continuous regions) models, another data structure called a transition region was required. The transition regions comprise of arcs (links) and waypoints to interconnect the different spatial types as shown in Figure 7 (a) (b) (c). When the agents are enroute towards their target locations, they utilise the available waypoints and arcs to transit across the different spatial types. Whilst transiting, the agents are able to maintain both their personal attributes (e.g. age, gender, body width) and their experiential attributes (e.g. cumulative wait times, velocity, distance travelled). For instance, when moving from continuous to fine nodes, the body width of the agent is adjusted to fit in the space available on that fine node. The body width of the agent is then reset to its initial setting if it re-enters a continuous space in its trajectory. In fact, all agents generated in the HSD model have a body width attribute irrespective of the spatial type in which they are generated. However, due to the limitations imposed by the granularity of the spatial types, the body width attribute is only utilised in the continuous model. 


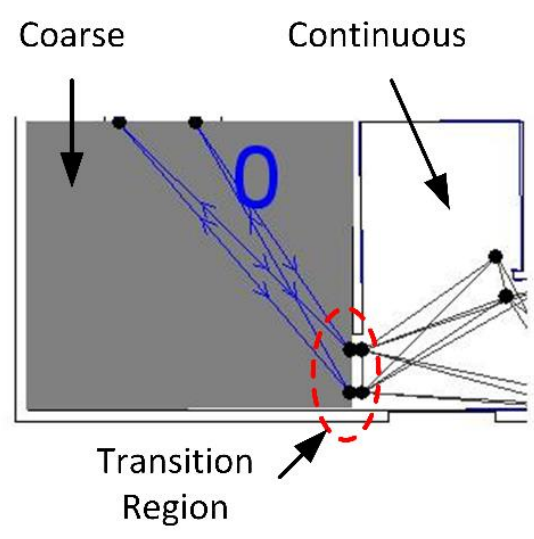

(a)

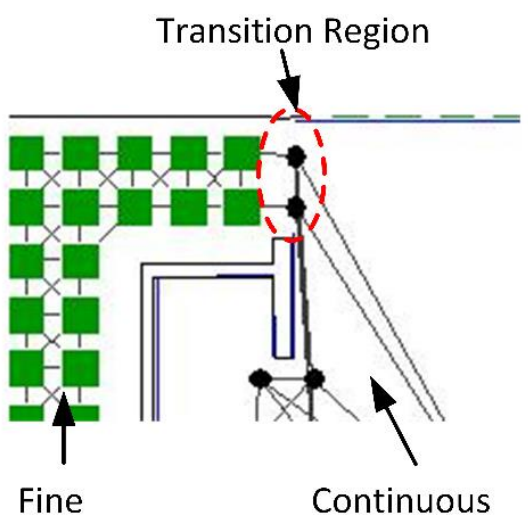

(b)

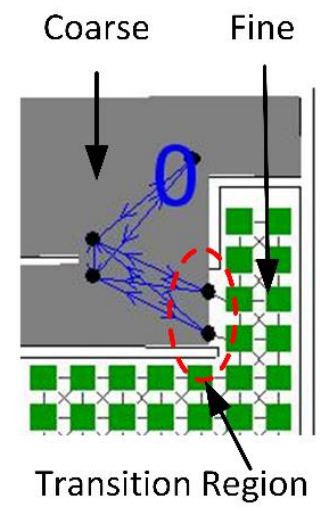

(c)

Figure 7 Transition Regions interconnecting different spatial types in HSD (a) Coarse and Continuous (b) Fine and Continuous (c) Coarse and Fine

The approaches adopted for simulating the transition of agents across the spatial types are outlined as follows:

Coarse and Continuous: The Coarse and Continuous regions represent the extremes in terms of the resolution. During the transition from Coarse to Continuous, the agents that have reached the end of the path in the Coarse region will use the adjacent waypoints in the Continuous as guides in order to enter the continuous space. The transition region also ensures that the agents do not overlap each other as they enter the continuous space. Upon entering the continuous space, the agents' behavioural routines allow them to spread out to use the available space. When the agents transit from continuous to coarse, they query the capacity of the coarse regions prior to entry. If the capacity of the coarse region is at its peak, the agents will wait in the continuous space until the coarse region capacity falls below its threshold.

Fine and Continuous: During the Fine to Continuous transition, agents from the Fine nodes use the waypoints for guiding their entry into the continuous space. Once in the continuous space, the agents will spread out to use the available space. When transiting from Continuous to Fine, agents will be shifted to empty nodes in the fine network. Otherwise in the absence of free nodes, the agents will exhibit waiting behaviour in the continuous region.

Coarse and Fine: When navigating from Coarse to Fine, the agents are shifted on available fine nodes that are connected to the arcs in the transition region. The transition is inhibited in the absence of available nodes. During the Fine to Coarse transition, the agents are relocated from their fine node to the connecting waypoint in the transition region as long as the capacity of the coarse region is not exceeded. 


\section{Considerations when interfacing Fine and Continuous}

The body widths of agents navigating in fine node networks are adjusted to fit on the nodes, but in fact, their original body width setting might be larger than the fine nodal sizes. As can be seen in Figure 8, an agent transiting from a fine node to waypoint $\mathrm{Wa}$, can end up in an invalid state (due to wall overlap) if it has a larger body width setting. Therefore, rather than connecting the arc between the fine node and $\mathrm{Wa}$, the arc is generated between the node and an offset location $\mathrm{Wb}$. The offset is chosen such that the distance between the wall boundary and $\mathrm{Wb}$ is equal to half the body width attribute of the largest agent. This ensures that all agents remain in a valid state following the transition. The same strategy is adopted for agents transiting from Coarse to Continuous.

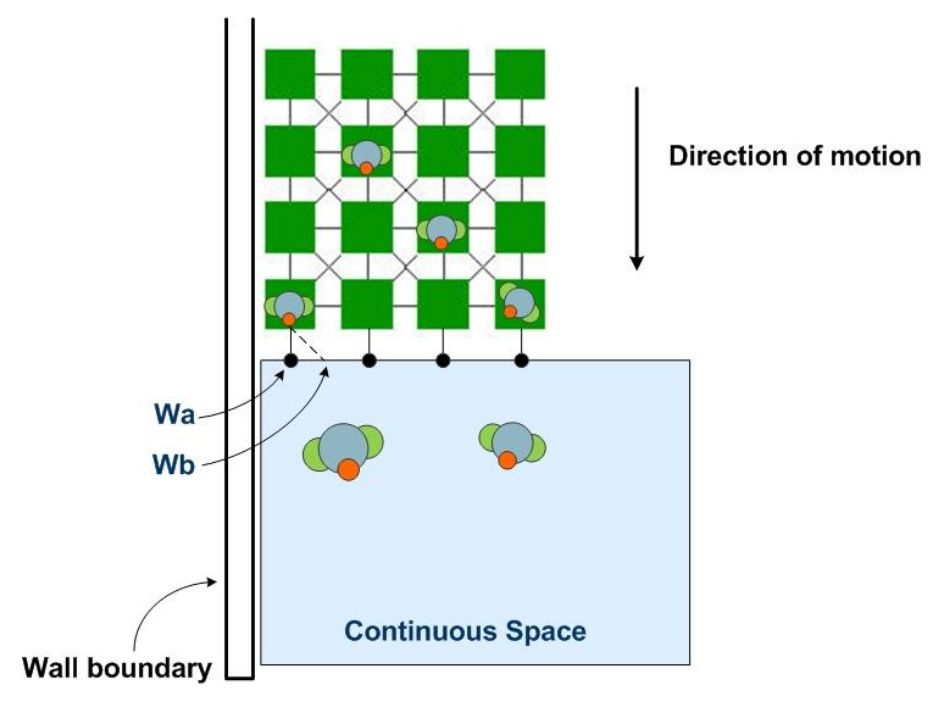

Figure 8 Considerations when interfacing Fine and Continuous

\section{Demonstration Case}

A fictional evacuation scenario was created to demonstrate the egress of 10000 occupants as a result of a fire originating in a forested region surrounding a residential area. This geometry was selected based on its scale and road network connectivity and is illustrated in Figure 9. Although the HSD approach allows mixing the 3 spatial types, however, for this case, the entire geometry was mapped using only Coarse regions and Fine nodal networks. The use of the Continuous region was not considered for this case as it would not provide the best computational efficiency on an urban scale. In our previous work [10], a preliminary verification of the Coarse model implementation was conducted whereby the Coarse model results were compared against those of the Fine. The Fine model has been extensively validated in numerous studies [16-19] and was considered suitable for verifying the Coarse model results. 
The overall dimensions of the outer boundary of the city was $2 \mathrm{~km} \times 2 \mathrm{~km}$. The assembly area is $200 \mathrm{~m} \times 200 \mathrm{~m}$ and is situated $200 \mathrm{~m}$ away from the upper city boundary. The assembly area consists of 10 compartments, each being $40 \mathrm{~m}$ x $50 \mathrm{~m}$ and connected to a $10 \mathrm{~m}$ exit. In the residential region, the entire road network is made up of dual carriageway roads that are $7 \mathrm{~m}$ wide and linked with $1.5 \mathrm{~m}$ wide pavements on either side of the road [30][31]. The network of roads together with the assembly area constitute a total free space area of $214260 \mathrm{~m}^{2}$. It can be assumed that the people who have reached the safe locations will be evacuated via vehicular transport. The use of vehicular transport for assisting evacuation processes in a Wildland-Urban Interface has been presented in a theoretical simulation framework by Ronchi et al. [32]. Also, past studies involving tsunami evacuations have shown that evacuees can move out of the affected areas faster on foot rather than using vehicles [33][34]. Traffic modelling of vehicles is beyond the scope of this work and is therefore not examined.
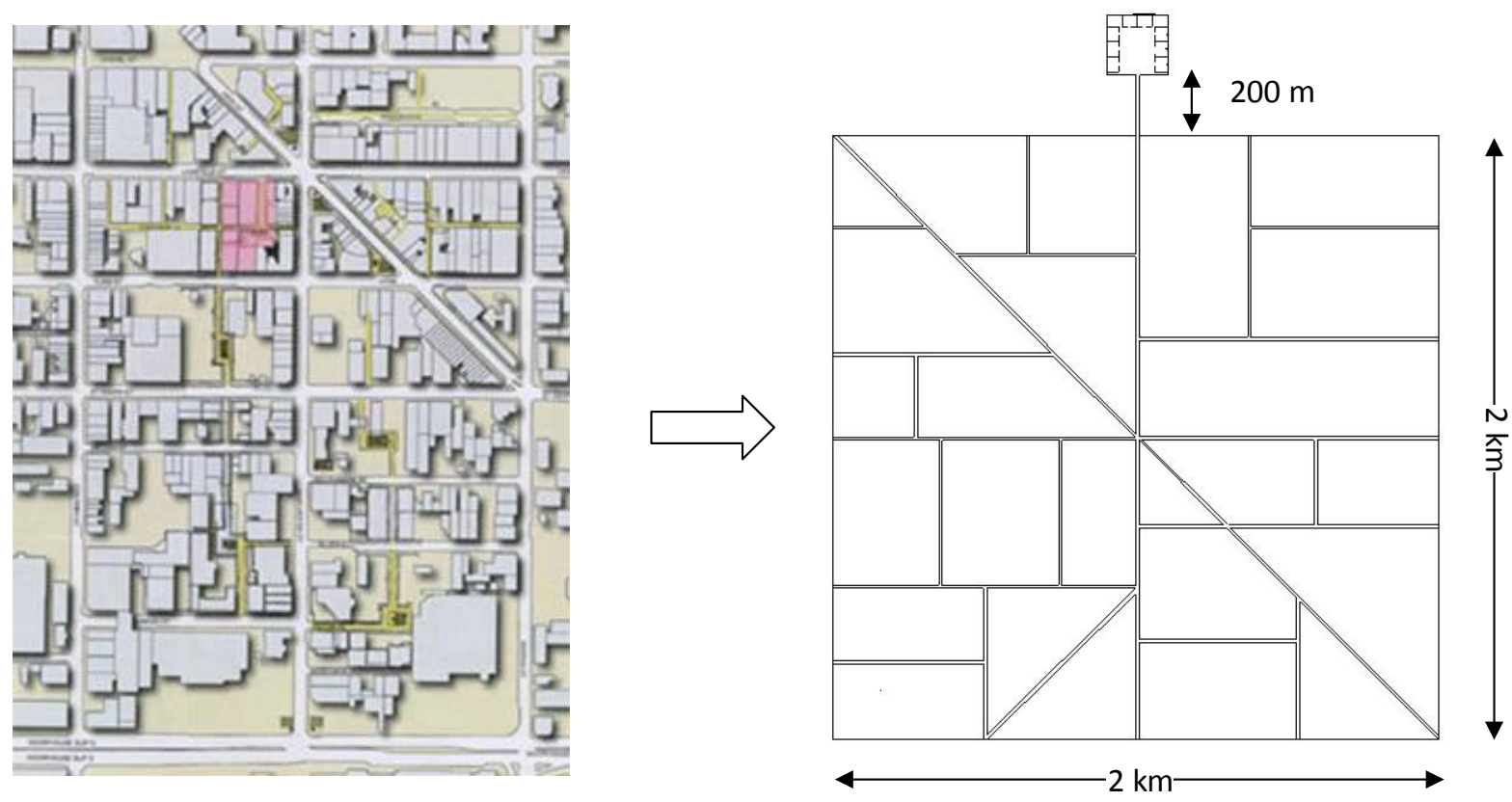

Figure 9 Large City Block geometry; empty spaces represent blocks of buildings surrounded by networks of dual carriageway roads

The simulations were run in three configurations namely, All-Coarse, All-Fine and Hybrid. In the first configuration, the entire free space area was modelled using Coarse regions. Out of the different types of Coarse regions that can be represented in the model, the Compartment regions were chosen. Given the width of the roads being modelled, the Compartment regions were found to be most appropriate, as they represent a general region in which agents enter or exit. The population was distributed randomly so that all roads, except the assembly area and the $200 \mathrm{~m}$ road linking it to the city, were occupied. Different portions of the population were assigned to the different exits in the assembly areas as follows; $10 \%$ of the population assigned to the first exit, $10 \%$ to the second and same percentages up to the tenth exit. The abilities of the people in the residential area were represented using different speed distributions coupled 
with behavioural and movement attributes as shown in Table 3. The agents were assigned zero response times in order to minimise the differences between the simulations run in different configurations. In addition, in order to allow the model to predict flow rates rather than be constrained by a predefined distribution, the flow rates at the exits were not capped.

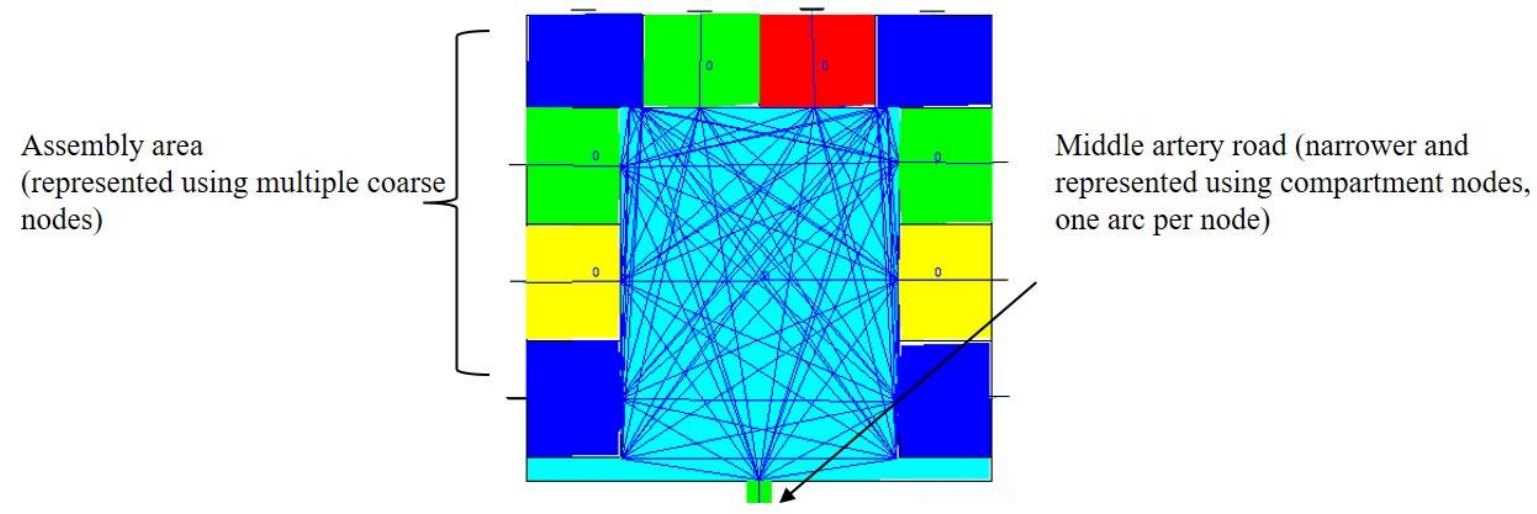

Figure 10 Connectivity of arcs in assembly area and middle artery road in All-Coarse

In the All-Coarse configuration, the Coarse regions in the assembly area and their connectivity to the middle artery road are as shown in Figure 10. The assembly area is modelled using multiple Coarse regions. Whereas the middle artery road is narrower and represented using Coarse regions as shown as in Figure 11.

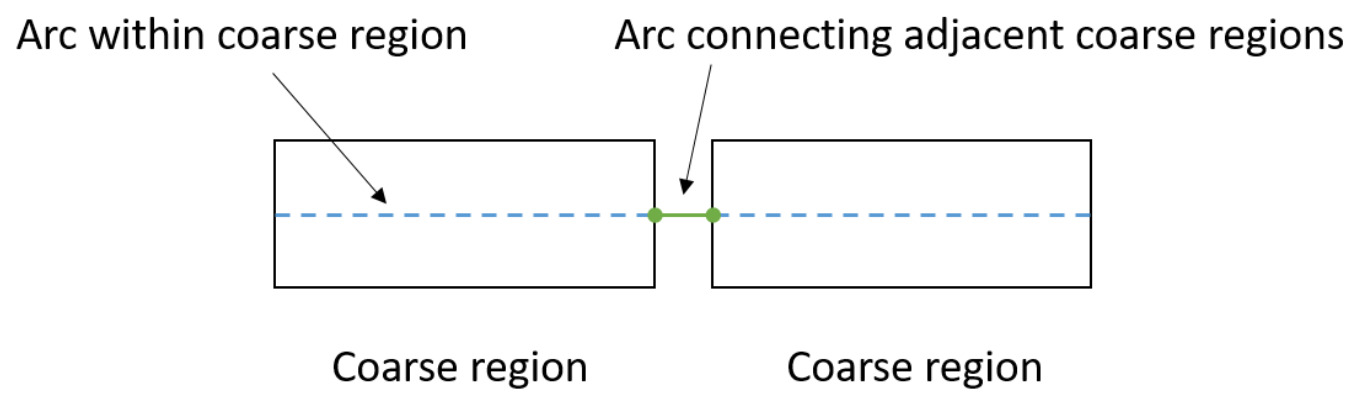

Figure 11 Connectivity of arcs in middle artery road

In the middle artery road, each coarse region is connected to other adjacent coarse regions using only one arc. This results in the creation of a single arc within each coarse region to allow agent movement.

In the second configuration, the entire free space area was populated using fine nodes. As buildingEXODUS is based on a stochastic model, 10 repeated runs were conducted to account for the randomness in evacuation times. For each repeat simulation, the agents were maintained in the same road segments, however their location within the segment was randomised. 
Table 3 Evacuee profile attribute default values

\begin{tabular}{|c|c|c|c|c|}
\hline \multirow{2}{*}{ Category } & \multirow{2}{*}{ Attribute } & \multirow{2}{*}{ Unit } & \multicolumn{2}{|c|}{ Default Value } \\
\hline & & & Min & Max \\
\hline \multirow{6}{*}{ Physical } & Mobility & - & 1.0 & 1.0 \\
\hline & Age & Years & 17 & 80 \\
\hline & Weight & $\mathrm{Kg}$ & 40 & 90 \\
\hline & Gender & - & \multicolumn{2}{|c|}{ Both male and female } \\
\hline & Agility & - & 2 & 7 \\
\hline & Height & $\mathrm{M}$ & 1.5 & 2 \\
\hline \multirow[t]{3}{*}{ Psychological } & Response Time & $\mathrm{S}$ & 0 & 0 \\
\hline & Patience & $\mathrm{S}$ & 1 & 5 \\
\hline & Drive & - & 5 & 15 \\
\hline \multirow[t]{4}{*}{ Travel Speeds } & Fast Walk & $\mathrm{m} / \mathrm{s}$ & 1.2 & 1.5 \\
\hline & Walk & $\mathrm{m} / \mathrm{s}$ & 1.08 & 1.35 \\
\hline & Crawl & $\mathrm{m} / \mathrm{s}$ & 0.24 & 0.30 \\
\hline & Leap & $\mathrm{m} / \mathrm{s}$ & 0.96 & 1.20 \\
\hline \multirow[t]{3}{*}{ Experiential } & Target Exit & - & \multicolumn{2}{|c|}{ Nearest Exit } \\
\hline & Familiarity & & \multicolumn{2}{|c|}{ Nearest Exit } \\
\hline & Itinerary & & \multicolumn{2}{|c|}{ Null } \\
\hline
\end{tabular}

In the third example, the demonstration case was represented using the Coarse-Fine configuration whereby the geometry was set up with $71 \%$ of the free space area modelled using Coarse regions and 29\% using Fine nodes. This configuration is depicted in Figure 12. The Coarse region approach was chosen for modelling the road segments surrounding the buildings in the far field because of its computational efficiency and its suitability for representing the uniform behaviours of the agents, which emerge as a result of their unidirectional motion within these road segments. All the Coarse regions converge into a middle artery road which leads to the assembly area. The middle artery and the assembly area are modelled entirely using a network of Fine nodes in order to account for more complex agent to agent and agent to structure interactions within those areas. The agent population and simulation set up used in the Coarse-Fine configuration was the same as the one used for the All-Coarse and All-Fine configurations. 


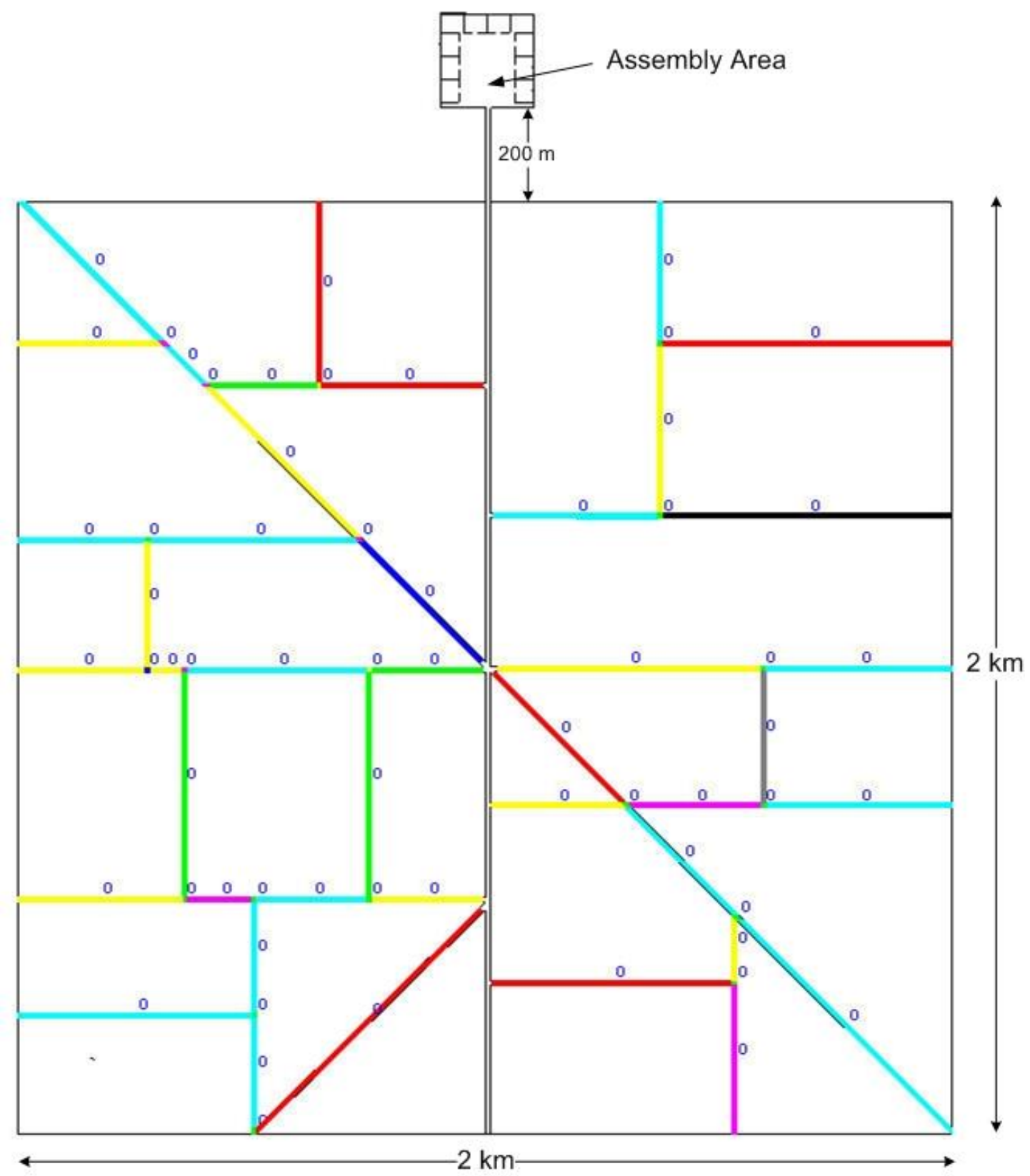

Figure 12 Large City Block geometry; shaded roads represented using coarse regions, assembly area and unshaded road in the middle of the city leading to assembly area represented using fine nodes.

In the Hybrid (Coarse-Fine) configuration, the main transition demonstrated by the agents is the Coarse $\rightarrow$ Fine. When agents traverse from Coarse regions to Fine nodes, they are repositioned on the Fine nodes which are connected by arcs to the Coarse region as described in Section 3.4. Prior to their transitions, the agents query the transition region to find the density in the space represented by the Fine node. If the density is high such that there are no available 
Fine nodes to transit to, the agent transitions are inhibited and consequently, the agents exhibit queuing within the Coarse region.

The Coarse model features two methods for connecting Coarse regions to Fine nodes as shown in Figure 13. The number of arcs generated using method $\mathrm{A}$ is much higher in comparison to the method B and therefore, agents within the Coarse region in method A will have to search for their target waypoint against a larger number of internal paths, thereby reducing performance. Moreover, due to the fewer number of internal paths in method B, this enables the users to better manage the arcs within the Coarse region. In these respects, the method B was preferred in this case. However, when using method B, it is important to apply the appropriate flow capacities to the arcs to ensure the agents do not get delayed unnecessarily in the coarse region.

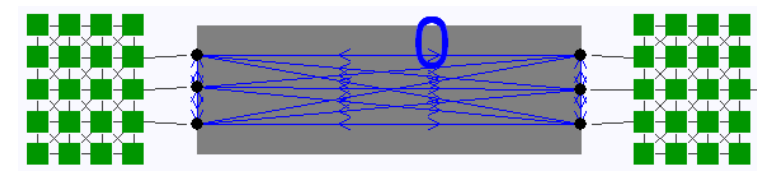

A

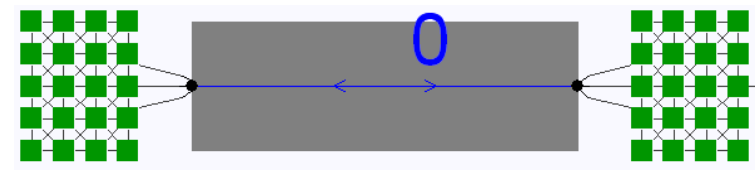

$\mathbf{B}$

Figure 13 Two methods of connecting a Coarse region (dark region) to set of Fine nodes (2D grid of nodes)

\section{Results and Discussion}

Figure 14 shows the evacuation time curves for the 3 configurations; All-Coarse, All-Fine and Hybrid. For each configuration, the result represents an average of the evacuation times for the 10 repeat simulations. The evacuation time results are as shown in Table 4. For the Hybrid case, we have a $95 \%$ confidence interval of $\pm 27.71 \mathrm{~s}$. In the case of the Fine node model, we have a $95 \%$ confidence interval of $\pm 25.53 \mathrm{~s}$ and for the all Coarse case the confidence interval was zero due to all ten runs producing the same result. It can be noted that the All-Coarse gives an evacuation time which is $11.9 \%$ faster than the All-Fine while the Hybrid's evacuation time is 3\% faster than the All-Fine. The difference between the All-Coarse and All-Fine results can be attributed to the inability of the Coarse model to explicitly represent microscopic agent interactions. As a result, the agents traverse the coarse regions at a faster rate, thereby leading to faster flow rates and consequently faster evacuation times in the All-Coarse configuration. 


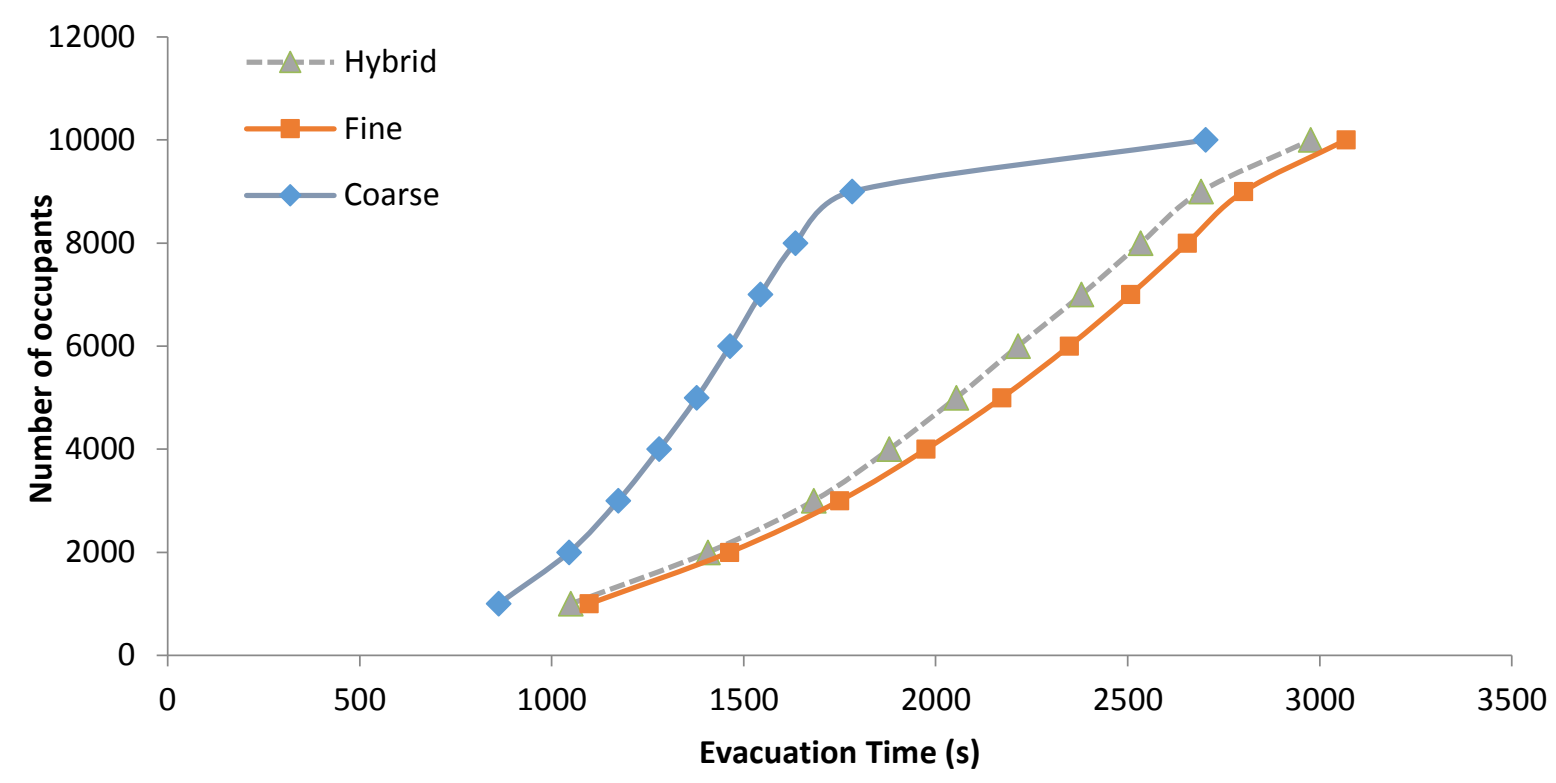

Figure 14 Time taken for a specific percentage of people to evacuate using All-Coarse, All-Fine and Hybrid spatial representation

When comparing the All-Coarse and All-Fine curves, it can be noted that in the Coarse model, the flow rate of the agents during the evacuation of the first 9000 agents is higher than the flow rate during the evacuation of the last 1000 agents. During the initial phase of the simulation in the Coarse model, there is no considerable build-up of population density within the single arcs in the middle artery Coarse regions, which results in faster flow rates. However, as the simulation progresses, increased queuing in the single arcs results in agents taking longer to enter the assembly area, thereby reducing the flow rates. The connectivity of arcs in the AllCoarse configuration is as shown in Figure 11. With this configuration, any build-up of agents within the single arcs will result in an overall reduction of agent flow rates. In the Hybrid configuration (Coarse-Fine), the middle artery road and the assembly area are represented using Fine nodes instead of Coarse. As can be seen from Figure 14, the Hybrid and All-Fine curves show similar trends implying that the Hybrid is producing evacuation dynamics which is more comparable to the Fine model. Yet the difference between the average total evacuation times between the Hybrid and Fine can be attributed to the inability of the Coarse regions (in the Hybrid configuration) to explicitly represent agent-agent interactions, thereby leading to faster flow rates and consequently slightly faster evacuation times.

Also from Figure 14, it can be noted that the Hybrid model captures likely pinch points in the structure better than the All-Coarse. It predicts areas of congestion/high density which would be missed in the All-Coarse model. When managing evacuation situations, it is important to identify the areas of congestion, since emergency services may need to be directed to these locations to manage any crowd build up. 
Table 4 Summary of results averaged over 10 simulations

\begin{tabular}{|l|l|l|l|}
\hline $\begin{array}{l}\text { Spatial } \\
\text { Representation }\end{array}$ & $\begin{array}{l}\text { Average Total } \\
\text { Evacuation Time (s) }\end{array}$ & $\begin{array}{l}\text { Standard } \\
\text { Deviation Total } \\
\text { Evacuation Time } \\
(\mathbf{s})\end{array}$ & $\begin{array}{l}\text { Average Run Time } \\
(\mathbf{s})\end{array}$ \\
\hline All-Fine & 3068.40 & 40.36 & 287.1 \\
\hline All-Coarse & 2702.99 & 0 & 5.0 \\
\hline Hybrid & 2976.82 & 43.81 & 163.3 \\
\hline
\end{tabular}

The average exit flow rates for each exit for each of the 10 cases are as shown in Table 5 below. The maximum difference in average flow rates for the Fine and Hybrid cases is 5\% whereby the Hybrid model is producing greater average flow rates than the Fine. These results are consistent with the overall average total evacuation time, with the greatest average flow rates being associated with the shortest overall total evacuation times.

Table 5 Average Unit Flow Rate for each case averaged over 10 simulations

\begin{tabular}{|c|c|c|c|c|c|c|c|c|c|c|}
\hline \multirow[t]{2}{*}{ Type } & \multicolumn{10}{|c|}{ Average Flow Rate (persons per second) } \\
\hline & $\begin{array}{l}\text { Door } \\
1\end{array}$ & $\begin{array}{l}\text { Door } \\
2 \\
\end{array}$ & \begin{tabular}{|l} 
Door \\
$\mathbf{3}$ \\
\end{tabular} & $\begin{array}{l}\text { Door } \\
4 \\
\end{array}$ & $\begin{array}{l}\text { Door } \\
5 \\
\end{array}$ & $\begin{array}{l}\text { Door } \\
6\end{array}$ & $\begin{array}{l}\text { Door } \\
7\end{array}$ & $\begin{array}{l}\text { Door } \\
8 \\
\end{array}$ & $\begin{array}{l}\text { Door } \\
9 \\
\end{array}$ & $\begin{array}{l}\text { Door } \\
10\end{array}$ \\
\hline Hybrid & 0.39 & 0.39 & 0.39 & 0.38 & 0.38 & 0.38 & 0.38 & 0.37 & 0.38 & 0.39 \\
\hline Fine & 0.37 & 0.38 & 0.38 & 0.37 & 0.37 & 0.37 & 0.36 & 0.36 & 0.37 & 0.37 \\
\hline
\end{tabular}

Table 6 illustrates the average distances travelled by 10 random agents in the Fine node model and the corresponding distances covered by the same agents in the Hybrid configuration. It can be noted that the distances travelled by the agents in the Fine and Hybrid cases are very similar. Although it is expected that the distances travelled by the agents cannot be exactly the same in the Fine and Hybrid due to evolving agent-agent and agent-environment interactions, however, viewing the extremely large size of the geometry and the differences in movement mechanism (in the transition regions), the comparable distances, based on inspection, show that the Hybrid model is producing very similar evacuation dynamics to the Fine model. 
Table 6 Distance travelled by agents in Fine and Hybrid configuration

\begin{tabular}{|l|l|l|l|l|l|}
\hline Agent & Gender & Age & $\begin{array}{l}\text { Weight } \\
(\mathbf{k g})\end{array}$ & \multicolumn{2}{|l|}{ Distance travelled (m) } \\
\hline & & & & Fine & Hybrid \\
\hline A & Male & 31 & 72.15 & 750.22 & 749.22 \\
\hline B & Male & 27 & 55.93 & 750.17 & 748.14 \\
\hline C & Male & 47 & 72.19 & 1013.32 & 1014.29 \\
\hline D & Female & 49 & 73.99 & 1282.77 & 1228.05 \\
\hline E & Male & 76 & 73.73 & 1072.6 & 1080.94 \\
\hline F & Male & 41 & 55.41 & 1676.79 & 1636.77 \\
\hline G & Male & 40 & 65.49 & 2123.84 & 2081.74 \\
\hline H & Female & 36 & 58.25 & 2245.67 & 2205.78 \\
\hline I & Male & 27 & 55.66 & 2418.3 & 2431.01 \\
\hline J & Female & 20 & 83.25 & 2649.47 & 2667.08 \\
\hline
\end{tabular}

Also shown in Table 4 are the average run times for the 10 repeat simulations for each case. The Hybrid model produces the fastest run time of $163.3 \mathrm{~s}$ which is $43.12 \%$ faster than the AllFine model. This significant speed up is due to the superior computational speed offered by the large proportion of Coarse regions in the Hybrid configuration.

In the light of the results shown in Figure 14 and Tables 4, 5 and 6, the HSD approach is seen to provide a substantial improvement in the run times of the simulation whilst maintaining the accuracy of the Fine nodal approach. The computational benefits offered by this approach make it suitable for the simulation of egress in extremely large environments. In addition, the results demonstrate that the algorithmic procedures employed in modelling the transitions of the agents across the interface regions operate consistently.

To demonstrate the scalability of the HSD approach, the simulations were run with a larger population of 50000 agents. For each configuration, the simulations were run 10 times. The average run times for the simulations are as follows: All-Coarse (2331.4 seconds), All-Fine (7271.9 seconds) and Hybrid (4760.7 seconds). From these results, it can noted that the Hybrid produces a run time which is $34.53 \%$ faster than the All-Fine. 


\section{Conclusion}

In this work, we have presented the use of Hybrid Spatial Discretisation model for the simulation of a large scale evacuation of a residential area, as a result of a surrounding forest fire. The defining characteristic of this hybrid model, as compared to other existing ones (discussed in Section 2), is that it is able to combine three techniques for representing space namely Coarse, Fine and Continuous within a single integrated model. The flexibility of the approach simulations to be run in multiple configurations namely All-Coarse, All-Fine, AllContinuous and Hybrid. As such, evacuation results can be obtained at multiple levels of resolution. To cater for time constrained simulations and allow decisions to be made in the fastest time possible (e.g. during an actual incident), the Hybrid model can be run in the AllCoarse configuration as it provides the highest computational performance. Also, the speed gains of the All-Coarse approach is useful for initial analyses, for example at the onset of a wildfire.

Another benefit of this hybrid approach is that it allows computational resources to be optimised by strategically combining different spatial techniques to different segments of a geometry. For instance, in the demonstration case, the Coarse approach has been used to represent areas in the far field and where there are homogeneous behaviours and movement patterns while areas requiring higher resolution of results (e.g. junctions, intersections and exits) have been modelled using the Fine node approach. As such, the hybrid approach has been seen to provide an improvement in run time by over $40 \%$ over the All-Fine approach when running the demonstration case with 10000 agents. Additional simulations with a population of 50000 agents have demonstrated an improvement in run time by over $34 \%$ when compared to the All-Fine approach. The improvement in run times indicate the scalability of hybrid approach with a potential for handling large geometries. Further work will entail the application of the HSD with varied configurations to investigate its adaptability for handling even larger evacuation problems.

\section{References}

1. WorldAtlas., 2018. Largest Fires in the World [online]. Available from: https://www.worldatlas.com/articles/the-blaze-of-oblivion-the-top-deadliest-wildfires-inthe-world.html [Accessed February 2018].

2. Cohen, J. (2008). The Wildland-Urban Interface Fire Problem, A Consequence of the Fire Exclusion Paradigm. Available from: https://foresthistory.org/wp-content/uploads/2017/01/Cohen.pdf [Accessed 25 February 2018] 
3. Westhaver, A., 2016. Why some homes survived: Learning from the Fort McMurray wildfire disaster, Institute for Catastrophic loss reduction.

4. Lindell, M.K., 2008. EMBLEM2: An empirically based large scale evacuation time estimate model. Transportation Research Part A, 42 (2008), 140 - 154.

5. Chen, X., Meaker, J.W., Zhan, F.B., 2006. Agent-Based Modeling and Analysis of Hurricane Evacuation Procedures for the Florida Keys. Natural Hazards, 38 (2006), 321338.

6. Kuligowski, E.D, Peacock, R.D, Hoskins, B.L.,2010. A Review of Building Evacuation Models; 2nd Edition, Technical Note 1680, Fire Research Division Engineering Laboratory, National Institute of Standards and Technology.

7. Lammel, G., Grether, D., Nagel, K., 2010. The representation and implementation of timedependent inundation in large-scale microscopic evacuation simulations. Transportation Research Part C, 18 (2010), 84-98.

8. Lovreglio, R., Ronchi, E., Maragkos, G., Beji, T., Merci, B., 2016. A dynamic approach for the impact of a toxic gas dispersion hazard considering human behaviour and dispersion modelling. Journal of Hazardous Materials, 318 (2016), 758-771.

9. Ronchi., E., Uriz, F.N., Criel, X., Reilly, P., 2016. Modelling large-scale evacuation of music festivals. Case Studies in Fire Safety, 5 (2016), 11-19.

10. Chooramun, N., Lawrence, P.J., Galea, E.R., 2012. An agent based evacuation model utilising hybrid space discretisation. Safety Science, 50 (8), 1685-1694.

11. Vassalos, D., Guarin, L., Vassalos, G.C., Bole, M., Kim, H., Majumder, J., 2003. Advanced Evacuation Analysis - testing the ground on ships. In: Proceedings of Conference on Pedestrian and Evacuation Dynamics, Greenwich 2003.

12. Gloor, C., Stucki, P., Nagel, K., 2004. Hybrid techniques for pedestrian simulations. In: Proceedings of $4^{\text {th }}$ Swiss Transport Research Conference, Ascona 2004.

13. Xiong, M., Tang, S., Zhao, D., 2013. A Hybrid Model for Simulating Crowd Evacuation. New Generation Computing, 31(3), 211-235. 
14. Xiong, M., Lees, M., Cai, W., Zhou, S., Low, M.Y.H., 2012. Hybrid modelling of crowd simulation. Procedia Computer Science, 1 (1), 57-65.

15. Tissera, P.C., Printista, M., Luque, E., 2012. A Hybrid Simulation Model to Test Behaviour Designs in an Emergency Evacuation. Procedia Computer Science, 9 (2012), 266-275.

16. Galea E.R, Galparsoro J.M.P (1994) A Computer Based Simulation Model for the Prediction of Evacuation from Mass Transport Vehicles. Fire Safety Journal, 22, pp 341 366.

17. Gwynne S, Galea E.R, Lawrence P.J, Filippidis L (2001) Modelling Occupant Interaction with Fire Conditions Using the buildingEXODUS Evacuation Model, Fire Safety Journal , 36, pp 327-357.

18. Galea E.R, Wang Z, Veeraswamy A, Jia F, Lawrence P.J, Ewer J (2008) Coupled Fire/Evacuation Analysis of the Station Nightclub Fire. In: Proceedings of 9th IAFSS Symposium Karlsruhe 2008, Germany, pp 465-476.

19. Galea E.R, Sharp G, Lawrence P.J (2008) Investigating the Representation of Merging Behavior at the Floor Stair Interface in Computer Simulations of Multi-Floor Building Evacuations. Journal of Fire Protection Engineering, 18, pp. 291-316.

20. Chooramun, N., 2011. Implementing a Hybrid Spatial Discretisation within an Agent Based Evacuation Model [Thesis], University of Greenwich.

21. Hui, X., Filippidis, L., Gwynne. S., Galea. E.R., Blackshields. D., Lawrence, P.J., 2007. Signage Legibility Distances as a Function of Observation Angle. Journal of Fire Protection Engineering, 17 (1), 41-64.

22. Pretorius, M., Gwynne, S., Galea, E. R., 2015. Large crowd modelling: an analysis of the Duisburg Love Parade disaster. Fire and Materials, 39(4), 301-322.

23. Oberhagemann, D., 2012. Static and dynamic crowd densities at major public events, Technical Report vfdb TB 13-01, German Fire Protection Association.

24. Anderson, J., Shiers, D., Steele, K., 2009. The Green Guide to Specification, 4th ed., IHS BRE Press: Watford, UK. 
25. Fruin, J., 1971. Pedestrian and Planning Design, Elevator World Inc. Educational Services Division, Alabama.

26. Kholshevnikov, V., Samoshin, D., 2008. Laws of Motion of Pedestrian Flow-Basics for Evacuation Modeling and Management, NATO Science for Peace and Security Series C: Environmental Security, 417-442.

27. Nelson. H., Mowrer, F., 2002. The SFPE Handbook of Fire Protection Engineering. Society of Fire Protection Engineers, 3rd ed., Bethesda.

28. Reynolds, C. W., 1999. Steering Behaviors for Autonomous Characters. In: the proceedings of Game Developers Conference 1999, San Jose, Miller Freeman Game Group, San Francisco, California, 763-782.

29. Buckmann, L.T., Leather, J., 1994. Modelling station congestion the PEDROUTE way, Traffic Engineering and Control, 35, 373-377.

30. Transport Watch UK (2010) Facts sheet 3: Widths and headroom [online]. Available from: http://www.transport-watch.co.uk/transport-fact-sheet-3.htm [Accessed 29 November 2010].

31. Department for Transport (2010) Inclusive Mobility [online]. Available from: http://www.dft.gov.uk/transportforyou/access/peti/inclusivemobility?page=3 [Accessed 29 November 2010].

32. Ronchi, E., Rein, G., Gwynne, S.M.V., Intini, P., Wadhwani, R., 2017. Framework for an integrated simulation system for Wildland-Urban Interface fire evacuation. In: Proceedings of the International Conference on Research and Advanced Technology in Fire Safety 2017, pp. 119-134.

33. Wood, N., Jones, J., Peters, J., Richards, K., 2018. Pedestrian evacuation modeling to reduce vehicle use for distant tsunami evacuations in Hawai' $i$, . International Journal of Disaster Risk Reduction, In Press.

34. Di Mauro, M., Megawati, K., Cedillos,V., Tucker,B., 2013. Tsunami risk reduction for densely populated Southeast Asian cities: analysis of vehicular and pedestrian evacuation for the city of Padang, Indonesia, and assessment of interventions. Natural Hazards. 68 (2), pp. 373-404. 